\title{
Study on the Tax Burden of Small and Micro- Enterprises
}

\author{
Baozhen Hou, Ming Lei \\ Xi'an International University, Xi'an, Shaanxi, 710077
}

\begin{abstract}
Small and micro enterprises are an important part of Chinese economic lifeline, play a decisive role in promoting national economic development, solving employment and enhancing comprehensive national strength. In the deepening development of economic globalization today, small and micro enterprises due to tax burden is too heavy, there has been development bottleneck. In view of this, this article analyzes the present situation of tax burden of small micro enterprises in China, and puts forward countermeasures to improve the operating environment of small micro enterprises.

Keywords: Tax Burden, Small and Micro Enterprises, Policy Study
\end{abstract}

\section{Introduction}

Small micro-enterprises for small micro-enterprises referred to. Different countries, different stages of economic development, different industries to define their standards are not the same, and with the economic development and dynamic changes. In 2011, the Ministry of Industry and Information Technology, the National Bureau of Statistics, the National Development and Reform Commission, and the Ministry of Finance jointly issued the Notice on Printing and Distributing the Standardization of Small and Medium-sized Enterprises. 4, Provisions for various industry standards, such as industry, For small and medium-sized enterprises with $<1000$ employees or operating income $<40$ million yuan. Among them, 8,300 employees, and operating income of 820 million yuan for the medium-sized enterprises; 820 employees, and 83 million yuan of revenue for small businesses; employees $<20$ or business income $<3$ 
million for the micro- enterprise. As the capillaries of the national economy, the small and micro enterprises are the growth force of Chinese Chaoyang economy, especially the technological innovation, an important way to expand employment, and also an important support to realize social stability.

\section{The Status of Small and Micro Enterprises in the National Economy}

Employment is the people's livelihood, employment has been guaranteed, tax revenue can be guaranteed in order to complete the expansion of domestic demand, the task of ensuring sustained economic growth. Small and micro enterprises provide $85 \%$ of urban and rural jobs, can fully configure the labor resources, improve social productivity, eliminate social disharmony factors, build a harmonious society, to a large extent to maintain social stability and promote economic development has an important role. Small and micro enterprises are mostly laid-off workers, aspiring entrepreneurs, one or more independent entrepreneurship, partnership founded, with a group of employment multiplier effect, that is, a group of people led by entrepreneurship employment. China is a big country of human resources, laid-off workers are more than an indisputable fact. The reform and opening up more than 30 years of practice has proved that Chinese employment and re-employment has made remarkable achievements in the world to maintain the employment situation is basically stable, small and micro enterprises play to promote employment, to absorb a large number of laidoff workers re-employment positive role, , Private individual economy and other small micro-enterprises contributed.

Most small and micro enterprises engaged in the tertiary industry, close to the market, close to the user, active in the market competition in the most intense field, is the mainstay of the market economy and market system micro-foundation. Small and micro enterprises start with low cost, the market adaptability, relatively large enterprises, small and micro enterprises to facilitate the operation, social shock small, low cost of reform, the introduction of new mechanisms faster. At the same time, the healthy development of small and micro enterprises is the driving force of economic growth and social progress. In recent years, science and technology small and micro enterprises quietly rising and rapid development, become the most active innovation in the main technological progress. Therefore, in the reform process, small and micro enterprises are often experimental area, is a breakthrough. The reform results of small and micro enterprises have provided beneficial experience for the reform practice of large enterprises and contributed to the excellent situation of common development of various economic sectors. 


\section{Small and Micro Enterprise Development Characteristics}

Small and micro enterprises is an important part of the development of Chinese market economy, in addition to capital and technology requirements of the relatively high special industries, small and micro enterprises covering almost all the national economy to the traditional processing and business-oriented enterprises. According to statistics, in the industry, wholesale and retail, leasing and business services industry and other small businesses in a total of 6.7 million small businesses, accounting for nearly $2 / 3$ of the total number of small microenterprises; and technology-based small and micro enterprises The number is about 477600 (only the information transmission industry, software and information technology services, small and micro enterprises), accounting for all kinds of small and micro enterprises accounted for only $4.62 \%$.

In accordance with the principle of "catching up and releasing small", the stateowned and collectively-owned sectors of small and micro-enterprises are gradually reduced. The proportion of non-public ownership economy has gradually increased, occupying a leading position. The ownership structure is diversified. According to the national small and micro enterprise development report released by the State Administration for Industry and Commerce in 2014, the proportion of small and medium-sized enterprises in foreign-funded enterprises is the lowest, accounting for 53.94 percent, 61.39 percent in stateowned collective enterprises, Accounting for $80.72 \%$, private enterprises constitute the main body of small and micro enterprises in China, including small businesses, including individual businesses in more than $97 \%$ of private enterprises.

As the small micro-enterprise employees, asset size and sales income and other indicators is relatively low, so small and micro enterprises show small size, less investment, easy to set up and so on. Small micro-enterprise operating mechanism is flexible, small micro-enterprise operators in the production and business activities have great autonomy, can make rapid response to the market. In addition, small micro-enterprise production and sales flexibility, many small and micro enterprises to "shop in front of the village" mode of production operation, sales on direct marketing to the local market-based, flexible operation.

\section{Small and Micro Enterprise Tax Burden of the Status Quo}

Chinese tax revenue increased year after year, the annual growth rate of more than $20 \%$. In order to complete the task of tax collection, the implementation process is often too stringent standards, the lack of flexibility, small microenterprise tax burden slowed down. At the same time, a variety of charges under various names, some units of tax collection, and some local government departments tend to small and micro enterprises as charges, assessment, fundraising focus on small and micro enterprises overwhelmed, or even crushed by fees. From the text to participate in the questionnaire survey of 90 small and 
micro enterprises in Wuhan, the actual tax revenue 13, funds and fees 27 , some of which costs are obviously not reasonable, such as urban education surcharge and education development fees repeated collection; And the role of price adjustment fund in name only; the implementation of many years, as early as the new wall materials should be outdated special fund, bulk cement and other special funds still exist and charged.

Enterprise entrance fee (enterprise certification, appraisal, assessment, upgrade), various social groups association fees, form of entertainment feast, a variety of Office of the Festival sponsorship fees, public welfare undertakings donations, remote or outside Exhibition fees, etc. In addition, companies sometimes have to pay money to deal with the surrounding environment and unknown security disputes and other issues. Although in recent years has been cleaned up to cancel a number of charges, but the inertia of policies and mechanisms, tax items are still numerous, the payment of fees is still a relatively heavy burden on enterprises. Especially in the context of dealing with the world financial crisis, the heavy tax burden makes the capital shortage of small and medium enterprises is even worse, the development of enterprises is inhibited, which in fact also depleted the tax source, resulting in the future tax ability of enterprises decline. In addition, because the charges are largely government behavior, the collection with a mandatory, so that companies are often in the ability to pay taxes and fees are limited, choose to pay taxes or taxes before the first payment, thereby reducing the macro tax, and some fees The object itself is part of the tax base, strong charges are easy to erode the tax base, the formation of tax expense tax.

\section{Policy Recommendations for Reducing the Tax Burden of Small and Micro Enterprises}

Chinese tax system and policy-making power concentrated in the central, local governments have little power, for small micro-enterprise tax incentives are also developed by the central. Through the analysis of Jiangsu and Zhejiang region small micro-enterprise tax incentives, the tax department in addition to the three provinces to implement some of the implementation of the national tax preferential policies, there is no provincial government for the development of small and micro enterprises substantive concessions. However, the specific situation of small and micro enterprises vary widely, unified preferential tax policies to make the economic efficiency of the policy greatly reduced. Therefore, it is necessary to reform the current tax management system, expand the local government tax management authority, to give local governments a certain tax policy-making power.

Tax authorities should make full use of modern network technology, through the tax website, micro-blogging, micro letter public number, the establishment of network service system, timely update personalized tax policy informed. The taxpayers can understand the tax policies correctly and comprehensively. The 
second is to simplify the approval procedure for the small and micro enterprises to enjoy the preferential taxation, financial subsidy, business handling and other matters, and to provide a "one-off" Stop "service; third is to simplify the record process, to reduce the link for the record examination and approval. The tax authorities should strengthen the contact and information sharing, to minimize taxpayers to repeat the declaration; Fourth, to increase government procurement policy support. Increase the share of small and micro enterprises in the government procurement plan, arrange government procurement projects specifically for small and micro enterprises.

The tax authorities should do a good job in paying tax services. First, it will comprehensively promote the construction of performance evaluation system for tax services, optimize the quality of tax services, clarify the responsibilities for small and micro enterprises, determine the target content, set service standards and work requirements, To strengthen the small micro-enterprise service awareness, and actively explore the tax-related matters for examination and approval Office of the Office of the pre-processing, and actively create "Internet Office of Taxation" to improve the efficiency of small and micro enterprises tax; Is to vigorously promote the service system, the establishment and improvement of public service platform to strengthen the public service platform network construction, establish and improve service standards and evaluation, enhance policy advice, business innovation, information services and other service functions for small and micro enterprises to provide quality The fourth is to safeguard the legitimate rights and interests of taxpayers, taxpayers to build taxrisk prevention mechanism.

At present, Chinese fees and charges on the enterprise complex, the charges of many departments, government departments generally re-charging, light management and light service tendencies. Through the survey, many companies can not guide the exact charges, fees and charges purposes. Therefore, it is necessary to regulate the management of charges involving enterprises, conscientiously implement the relevant policies and fees system. First, the government should make all kinds of charges transparent, the preparation of enterprise fees directory, and publicity to the community, so that enterprises clearly aware of their taxes paid; Second, strict fee system approval system, all fees, documents and fees to In accordance with the financial sector and the price department announced the implementation of the scope of government revenue; third is the agreement to the charges in line with the principle of voluntary business, service-oriented principle prohibit arbitrary charges or disguised charges to the enterprise; Fourth, the government should provide enterprises with charges Fifth, improve the supervision and inspection departments of the regulatory mechanism for the existence of such as self-reliance projects, such as fees and charges over the issue, such as the establishment of a large number of tax-Strictly according to the procedure processing, creates the good environment for the small micro enterprise's healthy development. 


\section{Conclusion}

Small and micro enterprises in the development of some deep-rooted problems facing the main tax burden is too heavy to reduce the real economic growth pressure to increase survival, the social service system is not perfect, low selfmanagement, scientific and technological innovation is weak, Financing difficulties, these problems to small and micro enterprises continue to bring difficulties. To alleviate the pressure of small and micro enterprise development, the state introduced a number of tax incentives. The impact of tax burden on the development of small and micro enterprises has been paid more and more attention by the government. Through the analysis of the burden of taxation on small and micro enterprises, the main reason is the unreasonable tax system design, overcharging local taxation, Unfair taxes and tax administration are not in place. How to reduce the tax burden of small and micro enterprises, give full play to the role of small and micro enterprises, is a subject worthy of study.

\section{Acknowledgement}

Xi'an Social Science Fund Project, Xi'an small and micro enterprises tax burden and fiscal policy research (16F71)

\section{References}

[1] Wang Jicheng. Small and Medium Enterprises 2013 Annual Report [J]. China Economic Report, 2014 (02)

[2] Wan Xianmeng. The Current Situation and Prospect of Small and Micro Enterprise Development [J]. Enterprise Research, 2013 (24)

[3] Tian Shubo, Jin Shaomei. Status and development of small and micro enterprises in China [J]. Business Economics, 2013 (21)

[4] Lu Yuanping, Zhu Yuexu, Wang Weiyu. Advancing the development of small and micro enterprises in China by using advanced foreign taxation system for reference [J]. Business Economics, 2003 (05)

[5] Deng Juqiu, Wang Xin, Wu Yinan. The Perfection of the Tax Policy System of Small and Small Enterprises in China [J]. Taxonomy Research, 2009 (08) 